\title{
A BLIND TEST METHOD FOR PREDICTION IN UNGAUGED BASIN
}

\author{
Ali CHAVOSHIAN¹, Kuniyoshi TAKEUCHI ${ }^{2}$, Hiroshi ISHIDAIRA ${ }^{3}$ and Yukiko \\ HIRABAYASHI 4 \\ ${ }^{1}$ Student member of JSCE, Graduate Student, Department of Civil and Environment Eng., University of Yamanashi \\ (4-3-11 Takeda, Kofu, Yamanashi, 400-8511, Japan) \\ 2 Member of JSCE, Dr. Eng., Professor, University of Yamanashi (Takeda, Kofu, Yamanashi, 400-8511, Japan) \\ ${ }^{3}$ Member of JSCE, Dr. Eng., Associate Prof., University of Yamanashi (Takeda, Kofu, Yamanashi, 400-8511, Japan) \\ ${ }^{4}$ Member of JSCE, Dr. Eng., Assistant Prof., University of Yamanashi (Takeda, Kofu, Yamanashi, 400-8511, Japan)
}

In this paper a blind test methodology is described and applied for inter-comparison of hydrological models using publicly available global data sets. The model inter-comparison involves making "blind" prediction of selected hydrological responses in the Mae Chaem basin $\left(3853 \mathrm{~km}^{2}\right)$ which is located in the North West of Thailand. Moreover the value of the publicly available data sets (e.g. various satellite-based precipitations) is investigated to determine their suitability for Prediction in Ungauged Basin (PUB). The distributed hydrological model BTOPMC is applied for runoff simulation. Transfer parameters from proxy catchment and a limited measurement method are used for model parameters estimation. Though each of the satellite-based precipitations underestimated the flow, GPCP was found best among them and it showed that the application of satellite-based data in PUB is encouraging. The study also prepared a base for model inter-comparison in the Mae Chaem basin.

Key Words: Blind test, ungauged basin, BTOPMC, satellite-based data, PUB

\section{INTRODUCTION}

There is no doubt that Prediction in Ungauged Basin (PUB) is interesting not only for hydrologist as a research field, but also for water resources manager as a tool for decision making. A blind test inter-comparison of hydrological models in a network of well gauged basins is useful for improvement of models for PUB purposes. Comparison of each model's results with observed data and/or other model's results when modelers use the same methodology and data will be able for them to evaluate goodness or badness of their models for a practical application in ungauged basins. A primary methodology for the "blind testing" was introduced by Ewen and Parkin ${ }^{1)}$ with an application using SHE model reported by Parkin et $\mathrm{al}^{2}$. However, they used a dense ground-based measurement as input of the model and their methodology has been considered only blind of observation data for model parameters estimation. Moreover, the application of the method was limited to a small Mediterranean experimental basin $\left(1 \mathrm{~km}^{2}\right)$.
In recent years development of globally covered satellite-based data makes themselves suitable to be used for prediction in ungauged or poor data basins. Therefore we are going to introduce a new blind test methodology using this kind of data. This methodology can be used for a model inter-comparison in a well gauged basin and for prediction of hydrological responses in an ungauged basin. The objectives of this study are to: (a) describe a methodology for blind test using hydrological models with globally covered data sets that are publicly available, (b) evaluate the quality of these data sets especially, satellite-based precipitation estimates for PUB, and (c) identify usefulness of runoff prediction using blind test method for water resources management and flood forecasting. For this we did a blind test runoff modeling using a distributed hydrological model for a humid tropical basin in the Asian monsoon region.

\section{STUDY AREA AND AVAILABLE DATA}

A well gauged basin, Mae Chaem, is selected for 
comprising results of blind test. Mae Chaem is a major sub-basin of Upper Ping River which is the largest tributary of Chao Phraya river system. Mae Chaem basin is located in the North West of Thailand. The Basin covers approximately $3853 \mathrm{~km}^{2}$ where the highest point is $2565 \mathrm{~m}$ above mean sea level and the lowest point is $282 \mathrm{~m}^{3}$.

Along with 11 rain gauges installed inside and nearby the basin by Thai government. 15 rain gauges were installed inside the basin as a part of Global Energy and Water Cycle Experiment (GEWEX) Asian Monsoon Experiment-Tropics (GAME-T). Most of the gauges (11 of 15) are installed in the elevation higher than $1000 \mathrm{~m}$ above MSL. Daily data of 1998 to 2003 is available3) 4) 5).

Moreover, observed daily discharge data of 1955 to 2003 at one gauging station, near to outlet of the basin, P.14 (18.23N, 98.56E) is available ${ }^{5)}$.

Areal average annual rainfall of the basin using a five year gauge-based data from 1998 to 2003 is $1426 \mathrm{~mm}$ and average annual flow volume in the P14 station is 1020 million cubic meters. The Thiessen polygons method is used for areal estimation of gauge-based rainfall.

\section{BLIND TEST METHOD}

The aim of detail description of new blind test method using publicly available data is to define a generally applicable framework for testing the fitness of hydrological models, of any type, for PUB. An inter-comparison of hydrological models using the same method and data makes it possible to answer why one model reproduces hydrologic response of study area better or worse than the others and which components of the models make such a difference. Moreover we are able to evaluate utility of publicly available data for PUB.

We proposed a four step blind test method:

1-Indicate object of test and kind of hydrologic responses to be blindly predicted.

2-Select model

3-Identify publicly available input data or generate them that are not based on traditional ground measurement in the study area.

4-Select values for the model parameters without using observation data of study area, so that the model closely simulates the interested hydrological behavior of the basin in question.

The following an application of the method is explained as a core study for inter-comparison of hydrological models in Mae Chaem basin.

\section{(1) Items to be blindly predicted}

We must perceive clearly that a blind test should be applied to provide a particular required output, and that not every thing predicted by a blind test will be accurate and important for water manager and what is acceptable will vary from test to test.

In this study, four hydrological responses regarding to the both normal and peak flow at the outlet of basin (P14) are blindly predicted: five year total flow (to show overall performance of the method by using the entire period that data was available), annual flow (to evaluate usefulness of the method for annual water budget applications like those used in decision support systems for annual water resource management), monthly runoff (to show performance of the method in simulating seasonal flow variation), and Maximum annual flood peak discharge (to evaluate utility of method for extreme hydrological responses simulation). Moreover, these were chosen for evaluation of both long-term and event-based blind test results.

\section{(2) Model}

A parsimonious version of BTOPMC in term of parameters need to be calibrated, is used. The BTOPMC is a distributed hydrological model, which is developed based on TOPMODEL concept to overcome the limitation of basin area, by dividing large basin to several blocks. The MuskingumCunge method is used for flow routing. Because of no observed snow in the study area, number of model parameters reduced to five parameters including: the saturated soil transmissivity $T_{0}\left(\mathrm{~m}^{2}\right.$ /h), the decay factor $m(\mathrm{~m})$ of $T_{0}$, the maximum storage capacity $S_{\text {rmax }}(\mathrm{m})$ of root zone due to vegetation, the initial value of averaged saturation deficit $S D_{b a r}(\mathrm{~m})$ and the Manning's roughness coefficient $n_{0}{ }^{6)}$.

\section{(3) Used data}

In this study, all used data of the model are obtained from publicly available global data sets. We are not going to discuss about scale problem or some other known issues of this data. Main emphasis is to show usefulness of them in term of blind test results for ungauged basin.

\section{a) Topographic data}

GTOP30 developed by USGS is used. Horizontal grid spacing of data is about 1 kilometer with $1 \mathrm{~m}$ vertical resolution.

\section{b) Land cover and soil types data}

$1 \mathrm{~km}$ resolution IGBP (International Geosphere-Biosphere Program) version 2.0 developed by USGS is used for land cover classification $^{12)}$. It shows that more than $90 \%$ of basin is covered by forest. A $5 \mathrm{~km}$ gridded soil type's data is used which produced by Food and Agriculture Organization (FAO). Soil types of basin are classified as $45 \%$ sand, $35 \%$ clay, and $20 \%$ silt. 
Table 1 Annual precipitation estimates over Mae Chaem basin (mm) from different data sources

\begin{tabular}{|c|c|c|c|c|}
\hline Year & GPCP & TRMM & PERSIANN & Rain gauges \\
\hline \hline 1998 & 916 & 776 & N/A & 990 \\
\hline 1999 & 1154 & 1157 & N/A & 1687 \\
\hline 2000 & 1339 & 1163 & 1033 & 1475 \\
\hline 2001 & 1129 & N/A & 828 & 1340 \\
\hline 2002 & 1251 & 1202 & 820 & 1637 \\
\hline
\end{tabular}

\section{c) Evapotranspiration}

Different methods for estimation of potential evapotranspiration are discussed in references and text books. In this study, the Shuttleworth-Wallace (S-W) method ${ }^{7}$ is used. In this parameterization, neither experimental measurement nor calibration is needed. The land cover classification is based on the IGBP land cover classification. The spatial and temporal variation of vegetation, LAI (Leaf Area index), is derived from the composite NOAA-AVHRR NDVI using the SiB2 method ${ }^{8)}$. The CRU TS 2.0 (Climate Research Unit) database provides us with the required meteorological data sets. All these data are publicly available. The developed S-W model is applicable at the global scale, particularly to the data-poor or ungauged large basins ${ }^{9}$. Based on the proposed model, average annual potential evapotranspiration for a five year period from 1998 to 2003 is $1460 \mathrm{~mm}$, and the yearly value varies from 1400 to $1600 \mathrm{~mm}$.

\section{d) Precipitation}

In recent years several sources are publicly available to obtain globally covered precipitation data sets. We can categorize them into ground-based (rain gauges or radar information) and satellite-based precipitation data.

One of the best sources for the first category is “Global Surface Summary of Day version 7” from NOAA-National Climatic Data center (NCDC) and World Meteorological Organization (WMO) that includes daily precipitation data for over 8000 worldwide stations from 1994 (updated weekly); are based on hourly and synoptic observation reported by the stations. In some previous researches utility of this data has been evaluated for PUB ${ }^{10}$. Besides of quality of ground-based publicly available rainfall data, one of the objectives of this study is to evaluate quality of satellite-based precipitation data. For this, TRMM (Tropical Rainfall Measurement Mission), PERSIANN (Precipitation Estimation from Remotely Sensed Information using Artificial Neural Networks), and GPCP (Global Precipitation Climatology Project) precipitations data are used.

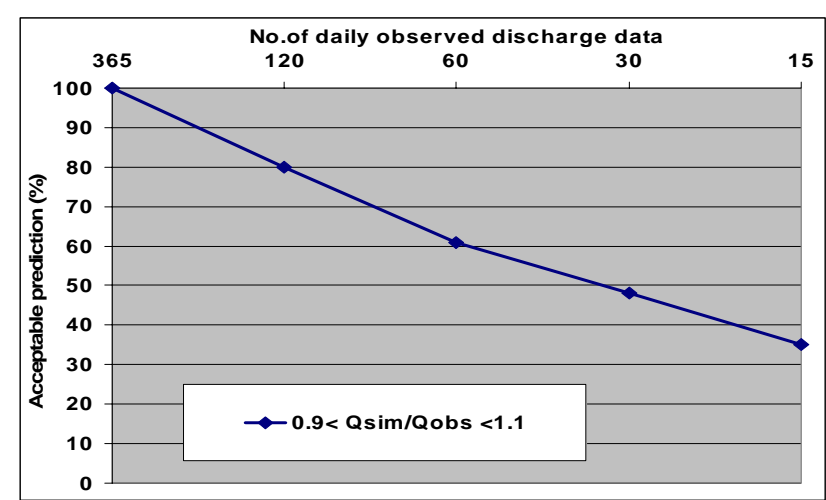

Fig.1 Split-sample method using a limited number of observed data.

GPCP global daily product is provided at onedegree spatial resolution by merging infrared (IR) and microwave (MW) satellite information with rain gauges observation. PERSIANN uses a neural network to estimate sub-hourly rainfall rates at 0.25-degree spatial resolution from geostationary satellite infrared images, based on the principle that surface rainfall rates are correlated with cloud top infrared brightness temperature and texture ${ }^{11)}$. The data of PERSIANN is available after the year 2000.

TRMM precipitation data is obtained from 3B42 version 6 (V6) and real time (RT) data. The TRMM 3B42 algorithm is to produce TRMM merged high quality infrared precipitation and root mean square (RMS) precipitation error estimates. These girdded estimates are on a 3-hour temporal and 0.25-degree spatial resolution. The data for year 2001 of TRMM is not available.

For blind test application of BTOPMC all the sub-daily precipitation data are accumulated to a daily period. Annual satellite-based rainfall and areal average annual rainfall of 26 gauges inside or nearby of Mae Chaem basin are shown in Table 1.

\section{(4) Parameters estimation and calibration}

Split-sample and proxy-catchment methods for parameters estimation and calibration in current use of hydrological models were discussed by Klemes ${ }^{12)}$. In the split-sample method, calibration of model's parameter set is only possible if some observations (usually discharge data) are available to compare with predicted variables. Therefore this method is not suitable for a blind test application of hydrological models in ungauged basins. Moreover, the critical issue here is how much data are necessary and sufficient for model calibration in a poor data basin with scarcity of observed data.

A bunch of partial blind test modeling of annual flow volume has been done. The partial blind test modeling means that we use a limited number of observed data for model calibration in manner of split-sample method. 


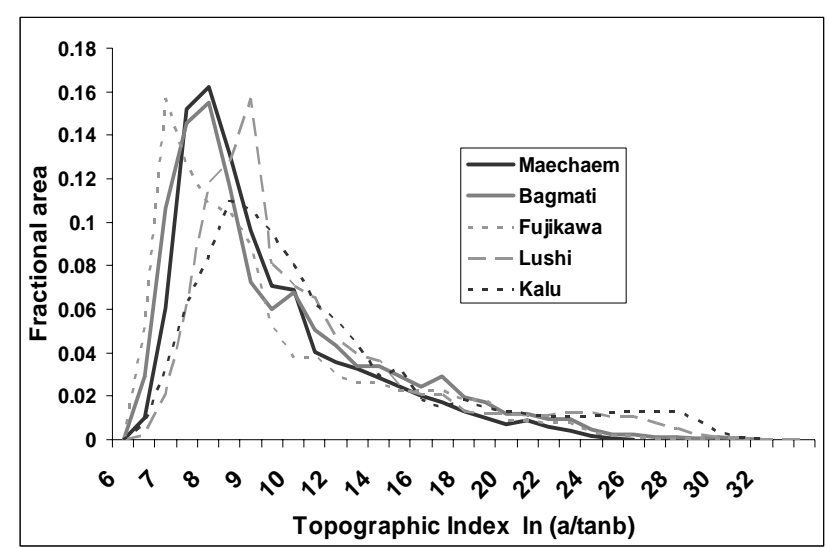

Fig.2 Comparison of Topographic Index

In these tests the relative error in partial blind flow volume estimation less than $10 \%$ is considered acceptable. Fig.1 shows that, 35\% acceptable result were obtained using only 15 days observed discharge data, which rises to near $50 \%$ when 30 days data were used.

The second method of the model's parameter estimation is to transfer parameters from a similar basin (proxy-catchment). The main question here is what the criteria for basin similarity are. The answer to the question depends on model types and the experimental judgment of modelers. One modeler may prefer just climate condition similarity and another one may based the assumptions of his model prefer some other physical features of the basin like topography or soil types, in addition to similar climate conditions.

The Topographic Index Eq.(1) or the Soil-topographic Index Eq.(2) are used as an index of hydrologically similarity in distributed hydrological model like BTOPMC. All points with the same value of the index are assumed to respond in hydrological similar way ${ }^{13)}$. In these equations $a$ is the area draining through a point from upslope, $\mathrm{T}_{0}$ is the local down-slope transmissivity at soil saturation, and $\beta$ is the local slope angle.

$$
\begin{aligned}
T I & =\ln (a / \tan \beta) \\
S I & =\ln \left(a / T_{0} \tan \beta\right)
\end{aligned}
$$

The topographic index distribution of high resolution DEM can be derived by using low resolution $\mathrm{DEM}^{14)}$. In this study GTOPO30 is used to calculate the Topographic Index from Eq.(1). The results for four basins in comparing with Mae Chaem basin are shown in Fig.2. The other four basins are Basmati (Nepal, $3500 \mathrm{~km}^{2}$ ), Fujikawa (Japan, $3500 \mathrm{~km}^{2}$ ), Lushi (China, $4400 \mathrm{~km}^{2}$ ), and Kalu (Sri Lanka, $600 \mathrm{~km}^{2}$ ). As it is clear from Fig.2, Bagmati basin has a similar trend with Mae Chaem in term of Topographic Index.
Table 2 Ratio of blind estimation of five year total flow volume over observation.

\begin{tabular}{|c|c|c|c|c|}
\hline Years & GPCP & TRMM & PERSIANN & Rain gauges \\
\hline \hline $1998-2003$ & $84 \%$ & $77 \%$ & $66 \%$ & $106 \%$ \\
\hline
\end{tabular}

In addition to Topographic Index, climate condition, land cover, and soil types of named basins were compared with Mae Chaem basin.

As a result Bagmati basin is assumed as the proxy catchment of Mae Chaem basin for parameters transferring. Bagmati basin located within middle mountain region of Nepal. The highest point of basin is $2625 \mathrm{~m}$ above mean sea level and the lowest point is $450 \mathrm{~m}$. Basin can be divided into three altitude/climate zone. A large part (more than 60\%) of the basin lies in temperate humid zone between 1000-2000m altitudes.

The Block-wise ability of BTOPMC makes it possible to select the parameters set from block of proxy catchment with maximum similarity. The selected block (sub-basin) for transferring parameters is covered by near $85 \%$ forest. Soil surface is formed by $50 \%$ sand, $20 \%$ silt and $30 \%$ clay. Rainy season is from June to end of September and average annual precipitation is $1520 \mathrm{~mm}$.

\section{RESULTS AND DISCUSSION}

Four blind tests simulation have been conducted in Mae Chaem basin. As mentioned before these tests are five year flow volume estimation, annual flow volume estimation, monthly runoff, and Maximum annual flood peak discharge estimation. Neither ground-based measurement nor calibration for observed data is used.

For each test, first BTOPMC was applied to Bagmati basin (proxy-catchment) for parameters estimation, then the parameters set has been transferred to Mae Chaem basin for simulation of proposed blind tests using publicly available data sets including satellite-based precipitation.

In the same way, one more test series conducted using gauge-based precipitation instead of satellite-based precipitation.

Result of each test is evaluated for observed data to identify efficiency of the new method. The following results can be considered as a core for model inter-comparison in study area.

\section{(1) Five year total flow volume test}

Total flow volume for five year period from 1998 to 2003 was simulated. The ratio (as a factor of blind test efficiency) of simulated flow volume over observed one is shown in Table 2. 
Table 3 Ratio of blind estimation of annual flow volume over observation.

\begin{tabular}{|c|c|c|c|c|}
\hline Year & GPCP \% & TRMM \% & PERSIANN \% & Rain gauges \% \\
\hline \hline 1998 & 95 & 81 & N/A & 103 \\
\hline 1999 & 76 & 76 & N/A & 110 \\
\hline 2000 & 89 & 77 & 72 & 103 \\
\hline 2001 & 86 & N/A & 68 & 106 \\
\hline 2002 & 81 & 79 & 61 & 107 \\
\hline
\end{tabular}

Table 4 Ratio of blind estimation of monthly runoff over observation for year 2000 .

\begin{tabular}{|c|c|c|c|c|}
\hline Mon. & GPCP \% & TRMM \% & PERSIANN \% & Rain gauges \% \\
\hline \hline Jan & 95 & 79 & N/A & 105 \\
\hline Feb & 90 & 83 & N/A & 102 \\
\hline Mar & 103 & 78 & 82 & 110 \\
\hline Apr & 107 & 92 & 74 & 99 \\
\hline May & 71 & 63 & 93 & 102 \\
\hline Jun & 85 & 72 & 64 & 98 \\
\hline Jul & 73 & 78 & 78 & 95 \\
\hline Aug & 93 & 81 & 51 & 94 \\
\hline Sep & 77 & N/A & 79 & 99 \\
\hline Oct & 84 & N/A & 61 & 101 \\
\hline Nov & 91 & 83 & 83 & 103 \\
\hline Dec & 104 & 88 & 89 & 114 \\
\hline
\end{tabular}

One year TRMM and two years PERSIANN data were not available. Therefore flow volume of TRMM and PERSIANN is calculated respectively for four and three years. It is obvious from Table 2 that satellite precipitation data resulted in an under estimation of flow volume mainly due to their less estimation of annual precipitation. The over estimation result of gauge-based precipitation could be due to uncertainty in parameter estimation.

\section{(2) Annual flow volume test}

Table 3 shows ratio of simulated annual flow volume over observed one. The GPCP resulted in a better estimation of annual flow volume compared to PERSIANN and TRMM data.

\section{(3) Monthly runoff test}

The ratio of monthly simulated runoff volume over observed one for the year 2000 is shown in Table 4 and Fig. 3.

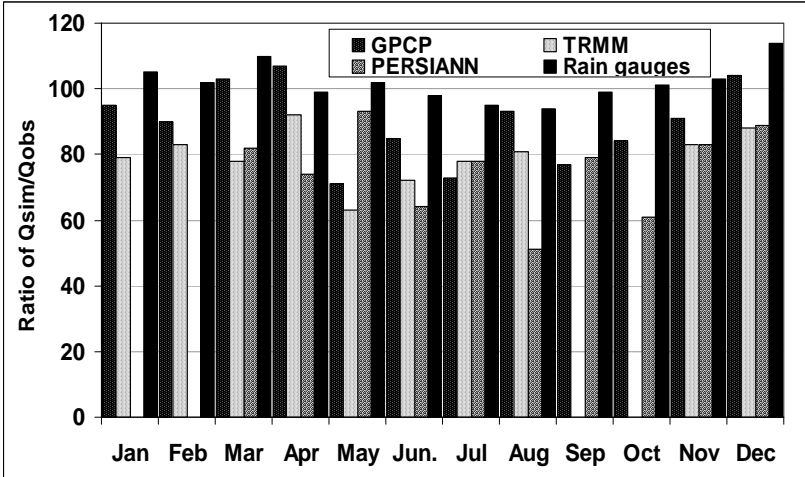

Fig.3 Ratio histogram of blind estimation of monthly runoff over observation for year 2000.

Table 5 Ratio of blind estimation of Maximum annual flood peak over observation.

\begin{tabular}{|c|c|c|c|c|}
\hline Year & GPCP \% & TRMM \% & PERSIANN \% & Rain gauges \% \\
\hline \hline 1998 & 74 & 56 & N/A & 109 \\
\hline 1999 & 70 & 58 & N/A & 111 \\
\hline 2000 & 61 & 46 & 53 & 107 \\
\hline 2001 & 83 & N/A & 35 & 108 \\
\hline 2002 & 72 & 70 & 62 & 104 \\
\hline
\end{tabular}

In Mae Chaem basin rainy season is from June to October. For rainy season the ratio is less than that of dry season. The results corresponding to the year 1998, 1999, 2001, and 2002 also showed the same trend. Moreover standard deviation of simulation over observation's ratio for monthly runoff test was found higher compared to five years or annual flow volume tests.

\section{(4) Maximum annual flood peak discharge test}

The ratio of simulated Maximum annual flood peak discharge over observed one is shown in Table 5. The result shows lack of applicability of the proposed method for event based modeling. Uncertainty of Maximum annual flood peak discharge using satellite-based precipitation data is too high to apply in ungauged basins for flood peak modeling. The main reason is that despite amount of satellite-based precipitation somehow shows a correlation with measured data, time distribution of satellite-based precipitation doesn't match with gauge-based one.

\section{CONCLUSION}

This study has presented a blind test methodology for PUB. It is shown that the proposed method can be applied in an ungauged basin for hydrological responses prediction. 
All of the necessary data were extracted from globally covered publicly available data sets. Three satellite-based precipitation data sources (GPCP, TRMM, and PERSIANN) are used in addition to gauge-based data within Mae Chaem basin. Similarity between different catchments is analyzed to identify a proxy catchment for transferring parameters. Bagmati basin was found to be a proxy catchment which closely resembles it in the hydrological behavior. A parsimonious version of BTOPMC was applied to blindly estimate the five year total flow volume, annual flow volume, monthly runoff volume, and flood peak discharge.

One of the advantages of this study is preparing core results for inter-comparison of hydrological models, which is important for PUB. Ratios of blind estimation over observation shown in Tables 2 to 5 can be considered as a base line values for model inter-comparison in Mae Chaem basin.

Another advantage of this research is to evaluate the utility of satellite-based precipitation for PUB. Despite the underestimation of flow volume by all satellite-based precipitation, the overall performance of their application is encouraging for long term modeling in ungauged basin. GPCP data is found to be better in predicting runoff compared to TRMM and PERSIANN. Moreover, the lesser the period of blind test simulation using satellite-based precipitation, the higher will be the predictive uncertainty.

The existence of strong orographic enhancement of precipitation in Mae chaem basin has been reported in earlier researches 3 4). This could be the reason for the under estimation of satellite-based precipitation compared with gauge-based data, majority of which are (11 of 15 GAME-T gauges) located in the higher altitude of the basin.

ACKNOWLEDGMENT: The authors gratefully acknowledge the MEXT, "Grant-in-aid for scientific research (A): Downscaling of global observations into local scale information" and University of Yamanashi $21^{\text {st }}$ COE program, "Research and education on integrated river basin management in Asian monsoon region" for opportunity and support of this research.

\section{REFERENCES}

1) Ewen, J. and Parkin, G.: Validation of catchment models for predicting land-use and climate change impacts. 1. Method, J. of Hydrology, Vol. 175, pp.583-594, 1996.

2) Parkin, G., O' Donnell, G., Ewen, J., Bathurst, C., O'Connell, P.E. and Lavabre, J.: Validation of catchment models for predicting land-use and climate change impacts 2.Case study for a Mediterranean catchment, J. of Hydrology, Vol. 175, pp.583-594, 1996.

3) Kuraji, K., Punyatrong, K. and Suzuki, M.: Altitudinal increase in rainfall in Mae Chaem watershed, Thailand, J. of the Meteorological Society of Japan, Vol. 79(1B), pp.353-363, 2001

4) Dairaku, K., Emori, S. and Oki, T.: Rainfall amount, Intensity, Duration and Frequency relationship in the Mae Chaem watershed in southeast Asia, J. of Hydrometeorology, Vol. 5, pp.458-470, 2004

5) Yoshitani, J., Tebakari, T. and Suvanpimol, C.: Research database for the IAHS decade on Prediction in Ungauged basins (PUB), Distributed in the meeting of PUB community of Japan in the IIS-The University of Tokyo, PWRI, March $1^{\text {st }} 2005$.

6) Takeuchi, K., Ao, T. Q. and Ishidaira, H.: Introduction of Block-wise use of TOPMODEL and Muskingum-Cunge method for the hydro-environmental simulation of a large ungauged basin, Hydrological Science Journal, Vol. 44(4), pp.633-646, 1999.

7) Shuttleworth, W. J. and Wallace, J. S.: Evaporation from sparse crops-an energy combination theory, Quarterly Journal of Royal Meteorological Society, Vol. 111, pp. 839-855, 1985.

8) Sellers, P.J., Los, S. O., Tucker, C. J., Justice, C. O., Dazlich, D. A., Collatz, G. J. and Randall, D. A.: A revised land surface parameterization (SiB2) for atmospheric GCMs. Part II: the generation of global fields of terrestrial biophysical parameters from satellite data, Journal of Climate, Vol. 9, pp. 706-737, 1996.

9) Zhou, M. C., Ishidaira, H., Hapuarachichi, H. P., Magome, J., Kiem, A. S. and Takeuchi, K.: Estimating potential Evapotranspiration using the Shuttleworth-Wallace model and NOAA-AVHRR NDVI to feed a distributed hydrological modeling over the Mekong river basin, J. of Hydrology, (2005 submitted, per review)

10) Chavoshian, A., Hirabayashi, Y., Ishidaira, H. and Takeuchi, K.: A Blind test of hydrological models intercomparison in the Mae Chaem, proceeding of annul conference of Japan Society of Hydrology and Water Resources, Tsukuba University, pp. 40-41, 2005.

11) Sorooshian, S., Hsu, K., Gao, X., Gupta, H. V., Imam, B. and Braithwaite, D.: Evaluation of PERSIANN system satellite-based estimates of tropical rainfall, Bulletin of American Meteorology Society, Vol. 81(9), pp. 2035-2046, 2000.

12) Klemes, V.: Operational testing of hydrological simulation models, Hydrological Science Journal, Vol. 31, pp. 13-24, 1986.

13) Beven, K. J.: Distributed hydrological modeling -applications of the TOPMODEL Concept, The J.WILEY press, pp.3-15, 1997.

14) Pradhan, N. R., Tachikawa, Y. and Takara, K.: A scale invariance model for spatial downscaling of topographic index in TOPMODEL, Annual Journal of Hydraulic Engineering, JSCE, Vol. 48, pp. 109-114, 2004.

(Received September 30, 2005) 